\title{
Theoretical Simulation and Experimental Study on Effect of Vacuum Pre-Cooling for Postharvest Leaf Lettuce
}

\author{
Enhai Liu", Xiaobo Hu², Shengyong Liu, ${ }^{1, *}$ \\ ${ }^{1}$ Key Laboratory of Renewable Energy of Ministry of Agriculture, Henan Agricultural University, Zhengzhou, China \\ ${ }^{2}$ Department of Food Engineering, Henan University of Animal Husbandry and Economy, Zhengzhou, China \\ *Corresponding author: ndshyliu@163.com
}

Received June 03, 2014; Revised July 25, 2014; Accepted July 31, 2014

\begin{abstract}
The effect of vacuum pre-cooling process on leaf lettuce was a complex process of heat and mass transfers. Based on the physical properties of leaf lettuce in vacuum pre-cooling process, an unsteady computation model was constructed to analyze the factors affecting vacuum pre-cooling. Some factors such as the pre-cooling temperature, pressure and quantity of the spray-applied water were verified throughout the experiment. The study showed that the measured and simulated values were basically the same, and the overall trend was similar. The lower the vacuum pressure, the greater the cooling rate lettuce and water loss rate. In this experiment, the water volume and pre-cooling pressure were the important factors during vacuum pre-cooling. This paper discovered that the quantities of leaf lettuce covered with water were equal to $4.211-5.977 \%$ of the total sample mass and the mass loss of the sample was $1.987-2.873 \%$. Under pre-cooling pressure of 600,1000 , and $1500 \mathrm{~Pa}$, the mass loss was 2.758, 2.701 and $1.929 \%$. After that, the results of calculation indicated that the quantities of capture water of the water-catcher was $1.607-2.567 \mathrm{~g}$, and the cooling capacity of the total sample was $3.722-5.946 \mathrm{~W}$ in vacuum precooling process. The results reveal that the model of leaf lettuce was fitted and it was confirmed by the experimental data.
\end{abstract}

Keywords: theoretical simulation, model, leaf lettuce, vacuum pre-cooling, cooling capacity

Cite This Article: Enhai Liu, Xiaobo Hu, and Shengyong Liu, "Theoretical Simulation and Experimental Study on Effect of Vacuum Pre-Cooling for Postharvest Leaf Lettuce.” Journal of Food and Nutrition Research, vol. 2, no. 8 (2014): 443-449. doi: 10.12691/jfnr-2-8-3.

\section{Introduction}

Vacuum pre-cooling at the right time could maintain postharvest quality of fruit better, and therefore prolong the time of freshness. Vacuum pre-cooling, which uses the principle of absorbing the latent heat of vaporization by water under vacuum pressure to rapidly cool freshly harvested fruits and vegetables, thus inhibiting respiration, is used to improve the storage quality of fruits and vegetables. Pre-cooling for the optimum time can prolong the maintenance of post-harvest fruit quality and freshness. The physical properties of fruit and vegetable products and their heat and mass transfer mechanisms during vacuum pre-cooling have been examined by numerous researchers. The effects of submerging vegetables in water on the weight loss of the products have been analyzed based on heat transfer theory. Wang et al. (2002) studied a model vacuum cooling process of cooked meat using finite elements and computational fluid dynamics for the simulation, while He et al. (2003) determined the mass transfer coefficients of vegetables and fruits during vacuum cooling. Theoretical methods have also been used for other vacuum cooling systems to determine a basis for optimizing the vacuum cooling processes. Jin et al. (2004) analyzed a heat/mass transfer model for Chinese cabbage in a vacuum chamber and recorded the changes in temperature and weight loss of the vegetable under variable pressure and relative humidity. Guo et al. (1999) studied the cooling processes of Chinese cabbage and Chinese kale in a vacuum cooling system, and divided the cooling stages into decompression, cooling and pressurerestoration. The effects of vacuum cooling and storage conditions on mushroom firmness and browning have also been investigated. Tao et al. (2007) reported the effects of vacuum cooling treatment and storage conditions on lipid oxidation, superoxide anion generation, superoxide dismutase, catalase, peroxidase and polyphenoloxidase in mushrooms. Cheng et al. (2006) analyzed a multi-stage vacuum cooling process for cabbage. The vacuum precooling technology had been proven to be one of the most efficient rapid cooling methods available (Sun, D.W. \& Zheng, L., 2006). Accompanying with the increase of the living pace, fruit and vegetable was the important source of vitamin, mineral and dietary fiber, which was indispensable to maintain human healthy body and supply nourishment (Wang, L.J. \& Sun, D.W., 2001). Besides, vacuum pre-cooling could enhance the quality of fruit and vegetable, as opposed to processed fruit and vegetable 
products without vacuum pre-cooling had an absolute advantage (McDonald, K. \& Sun, D.W., 2000). Schmidt et al. (2010) developed and evaluated integrated processes of cooking and vacuum cooling of chicken breast cuts in a same vessel aiming at avoiding product manipulation and reducing the processing time. He et al. (2013) studied aimed to determine the effects of vacuum cooling on the enzymatic antioxidant system of cherry and inhibition of surface-borne bacteria during storage. Zhang et al. (2013) investigated the use of vacuum cooling to chill cooked beef dices, strips and mince in bulk to core temperature below $4^{\circ} \mathrm{C}$, reported the Cooling parameters and some product quality properties were evaluated and compared to those obtained after conventional cooling methods.

Namely, on condition that effect of vacuum pre-cooling for fruit and vegetable would be affected some factors such as pre-cooling temperature, water spraying quantities, pre-cooling pressure. It could be concluded that the research on the vacuum pre-cooling of leaf lettuce was relatively rare. Little was known about the effect of vacuum cooling treatment as a factor that affected heat and mass transfer mechanisms under different conditions. How to effectively control the late of weight loss during vacuum pre-cooling, look for the best technological conditions to solve the problems. It is key factor to determine the best process conditions for effectively controlling the rate of weight loss during vacuum precooling. In this study, leaf lettuce samples were shaved to form bundles with a diameter of $4 \mathrm{~cm}$, at the Maozhuang Science and Technology Park, Henan Agricultural University. The physical properties of the lettuce were analyzed, and an unsteady computational model was used to determine the factors that most affect the vacuum precooling of lettuce. An experiment was also performed in a vacuum chamber using the MATLAB method, where the degree of vacuum was pre-set, and the temperature change and weight loss of leaf lettuce under variable pressure were determined. The quantities of capture water of the water-catcher, the cooling capacity of the s total sample were calculated in vacuum pre-cooling process, respectively.

\section{Model Establishment}

\subsection{Model Description}

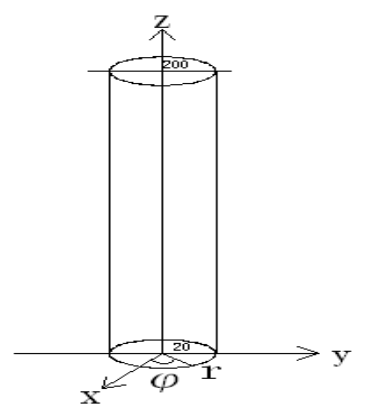

Figure 1. Physical model of leaf lettuce

Theoretical analysis and practice were combined in this study. Samples of leaf lettuce were shaved to form a bundle with diameter close to 4 centimeter and length close to 20 centimeter respectively. The physical model used in the study is illustrated in Figure 1. Considering the internal heat conduction and the heat and mass transfer on the leaf surface, the following assumptions were made for the model calculations: (1) the physical properties of the leaf lettuce were constant during vacuum cooling; (2) heat transfer from respiration, convection and radiation during vacuum pre-cooling were not considered; and (3) based on the refrigeration system, water diffusion inside the lettuce was ignored during vacuum pre-cooling.

Based on these assumptions, the two-dimensional cylindrical heat transfer equations for an unstable state were as follows:

$$
\rho c \frac{\partial T}{\partial t}=\frac{1}{r} \frac{\partial}{\partial r}\left(\lambda r \frac{\partial T}{\partial r}\right)+\frac{1}{r^{2}} \frac{\partial}{\partial \phi}\left(\lambda \frac{\partial T}{\partial \phi}\right)+\frac{\partial}{\partial z}\left(\lambda \frac{\partial T}{\partial z}\right)+q_{v}
$$

Initial condition: $\mathrm{t}=0, T=T_{0}(0<\mathrm{r}<\mathrm{R})$;

$$
\begin{gathered}
\text { Boundary condition: } \mathrm{r}=0,\left.\frac{\partial T}{\partial r}\right|_{r=0}=0(\mathrm{t}>0) ; \\
\mathrm{r}=\mathrm{R},\left.\quad \lambda \frac{\partial T}{\partial t}\right|_{r=R}=-h\left(T_{\text {sur }}-T_{\text {air }}\right)-q_{v}
\end{gathered}
$$

The applicable properties of leaf lettuce were expressed as: $\rho$, density $\left(\mathrm{kg} \mathrm{m}^{-3}\right) ; c$, specific heat capacity $\left(\mathrm{J}\left[\mathrm{kg}^{-}\right.\right.$ $\left.\left.{ }^{1} \cdot \mathrm{K}^{-1}\right]\right) ; \lambda$, coefficient of thermal conductivity (W $\left(\left[\mathrm{m}^{-1} \cdot \mathrm{K}^{-}\right.\right.$ $\left.\left.{ }^{1}\right]\right) ; r, \phi, z$ cylindrical coordinate system; $T$, temperature (K); $T_{\text {sur }}, T_{\text {air }}$, surface temperature of leaf lettuce and ambient temperature, respectively (K); $t$, time (s); $h$, heat transfer coefficient ( $\left.\mathrm{W}\left[\mathrm{m}^{-2} \cdot \mathrm{K}^{-1}\right]\right)$; and $q_{v}$, inner heat source $\left(\mathrm{W} \mathrm{m}^{-3}\right)$, where $q_{v}$ is calculated as:

$$
q_{v}=-1000 \frac{R_{e v}}{V} \frac{d m}{d t}
$$

$R_{e v}$ is the latent heat $\left(\mathrm{kJ} \mathrm{kg}^{-1}\right) ; V$ is the volume $\left(\mathrm{m}^{3}\right)$; and $\frac{d m}{d t}$ is the mass loss rate $\left(\mathrm{kg} \mathrm{s}^{-1}\right)$.

Convection and radiation heat transfer were neglected in the low-pressure environment. We used a VFDS-2000 vacuum pre-cooling dry dual-use machine (Shanghai in China Co., Ltd.) with a vacuum volume of $0.1 \mathrm{~m}^{3}$. The optimum conditions were initial temperature, $24^{\circ} \mathrm{C}$; final temperature, $5^{\circ} \mathrm{C}$; initial pre-cooling pressure, $600 \mathrm{~Pa}$; and final pressure, $1500 \mathrm{~Pa}$. We analyzed the temperature changes and weight loss of the leaf lettuce under variable pressure during the vacuum pre-cooling process. A detailed description of the model, devised to reduce error resulting from the use of different lettuce samples during the pre-cooling test, is provided below.

$$
\begin{gathered}
\rho c \frac{\partial T}{\partial t}=\frac{\lambda}{r} \frac{\partial}{\partial r}\left(r \frac{\partial T}{\partial r}\right)+q_{v} \\
\left.\lambda \frac{\partial T}{\partial t}\right|_{r=R}=-1.77 \times 10^{6} R_{e v} \frac{d m}{d t}
\end{gathered}
$$

\subsection{Model Solution}

According to guidance for fresh fruits and vegetables, $\lambda=0.61 \mathrm{~W}\left(\mathrm{~m}^{-1} \cdot \mathrm{K}^{-1}\right)$ and $c=4.11 \mathrm{~J}\left(\mathrm{~kg}^{-1} \cdot \mathrm{K}^{-1}\right)$. For the MATLAB calculations, two groups of experimental materials were selected: group I (40.47, 41.75, 38.28 and $52.02 \mathrm{~g})$, and group II (35.43, 42.95 and $56.59 \mathrm{~g})$. 
According to the basic theory of mass transfer coefficients, the weight loss of the leaf lettuce during vacuum cooling storage can be written as:

$$
\frac{d m}{d t}=k_{m} k_{\varepsilon} V\left(P_{i}-P^{\prime}\right)
$$

Where $k_{m}$ is the mass transfer coefficient; $k_{\varepsilon}$ is the proportionality constant (0.62); $P_{i}$ is the vacuum chamber pressure, $\mathrm{Pa}$; and $P^{\prime}$ is the saturation pressure corresponding to temperature $\mathrm{T},(\mathrm{Pa})$, the equation can be written as:

$$
P^{\prime}=e^{\left(23.1964-\frac{3816.44}{T+227.02}\right)}
$$

Temperature calculation of the leaf lettuce during vacuum pre-cooling process is provided below.

$$
\begin{aligned}
& \left.\frac{\partial T}{\partial r}\right|_{r=0}=0(\mathrm{t}>0), \\
& \rho c \frac{\partial T}{\partial t}=-1.80 \times[2500.8-2.42(T+273.15)]\left(P_{i}-P^{\prime}\right)(8) \\
& \left.\lambda \frac{\partial T}{\partial t}\right|_{r=R}=1.77 \times 10^{6}[2500.8-2.42(T+273.15)] \frac{d m}{d t}(9)
\end{aligned}
$$

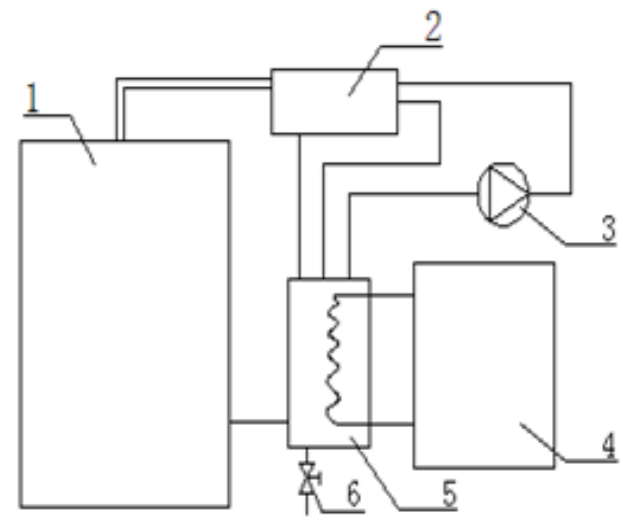

a. Structural diagram

\section{Experimental Verification}

An unsteady computational model was constructed based on heat and mass transfer mechanisms to analyze the factors affecting leaf lettuce during vacuum precooling, and the model was verified experimentally. Changes in the vacuum chamber pressure, temperature and quality of leaf lettuce over time were analyzed and compared.

\subsection{Experimental Apparatus}

Vacuum pre-cooling equipment used Shanghai in China Co., Ltd. VFD-2000-type vacuum cooling test machine, mainly by the refrigeration system, vacuum system and the acquisition and control system. As shown in figure 2, the vacuum system used a $2 \mathrm{XZ}-4$ rotary vane vacuum pump with a pumping rate of $4 \mathrm{~L} \mathrm{~s}-1$ and a speed of 1400 rpm. Four thermocouple temperature measurements were established in the vacuum chamber and a vacuum pressure sensor was installed to collect data. The control system consisted of a programmable logic controller, personal computer and electrical components, with system parameters set for timely data collection, storage and processing. Figure 2 presents experimental table for the vacuum pre-cooling test machine.

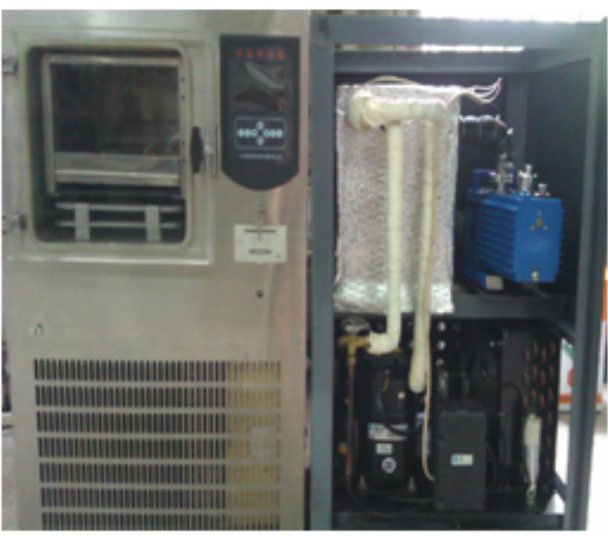

b. Practicality diagram

1. Pre-cooling chamber; 2.Control systems; 3.Vacuum-pump; 4.Compressor; 5.Condenser; 6.Drain valve.

Figure 2. Experimental table for the vacuum pre-cooling test machine

\subsection{Experimental Material and Test Method}

Screening and binding into cylindrical rolls, subsamples of lettuce were taken to the Mao Zhuang Science and Technology Park, Henan Agricultural University for analysis. The samples were weighed on an LT502E electronic balance with maximum load of $500 \mathrm{~g}$, sensitivity of $0.01 \mathrm{~g}$, and level-III precision. Group-I (40.47, 41.75, 38.28 and 52.02 g) and group-II (35.43, 42.95 and $56.59 \mathrm{~g})$ samples were placed in the vacuum chamber on racks for the comparative test. After precooling the samples were weighed and the test was repeated with different control parameters. Having selected leaf lettuce, after simple treatment, we shut down the experimental machine door in vacuum tank, start the computer test program and vacuum system.

\section{1) Temperature Test}

During the test, in accordance with the test requirements of the thermocouple arranged in the geometric center of the cylindrical sample, with the edge of the measuring points of the test sample arranged as shown in Figure 3. The vacuum chamber door lock open test device, the collection test data. Pre-wet processing leaf lettuce pre-cooling mass loss, as shown in Table 1.

\section{2) Pressure test}

In order to test the effects of the pressure in vacuum container on vacuum pre-cooling for lettuce, a pressure sensor was placed in the vacuum chamber pressurerecording line (600, 1000 and $1500 \mathrm{~Pa}$, data collection interval=30 s), and Microsoft Excel was used for editing. Changes in the material and temperature were measured. The weight loss of leaf lettuce under variable pressures is shown in Table 2. 
Table 1. Pre-wet processing leaf lettuce pre-cooling mass loss

\begin{tabular}{cccc}
\hline Group-I & Dry weight(g) & $\begin{array}{c}\text { The sample mass(after spray } \\
\text { water)(g) }\end{array}$ & $\begin{array}{c}\text { Water spraying quantities(g) sample mass(after pre- } \\
\text { cooling })(\mathrm{g})\end{array}$ \\
\hline Sample 1 & 40.47 & - & - \\
Sample 2 & 41.75 & 43.51 & 1.76 \\
Sample 3 & 38.28 & 40.25 & 1.97 \\
Sample 4 & 52.02 & 55.14 & 3.12 \\
\hline
\end{tabular}

Table 2. Weight loss of leaf lettuce under the variable pressure

\begin{tabular}{|c|c|c|c|c|}
\hline group-II & Before pre-cooling $(\mathrm{g})$ & After pre-cooling(g) & Mass loss rate(\%) & Final pressure(Pa) \\
\hline Sample 5 & 35.43 & 34.45 & 2.762 & 600 \\
\hline Sample 6 & 42.95 & 41.71 & 2.702 & 1000 \\
\hline Sample 7 & 56.59 & 54.78 & 1.931 & 1500 \\
\hline
\end{tabular}

\subsection{Analysis and Discussion}

The simulation and experimental analyses examines the effects of the leaf lettuce submersion on weight loss: the lower the vacuum pressure, the more rapid the water loss and the greater the cooling rate. The theoretical results and measured values matched well, and the differences between them were small. Heat and mass transfer mechanisms based on vacuum cooling, pressure control during cooling theoretical modeling and experimental testing of the water loss rate and sample temperature are presented in Figure 4 using the values shown in Figure 8. The computational model of leaf lettuce was fitted and it was confirmed by the experimental data.

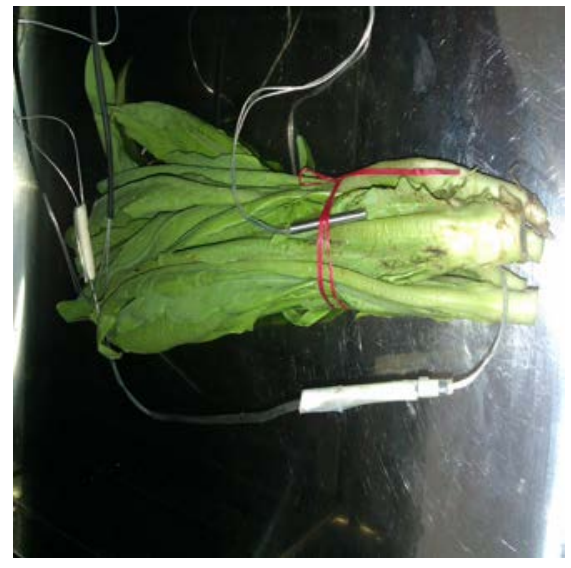

Figure 3. The measurement points arrangement

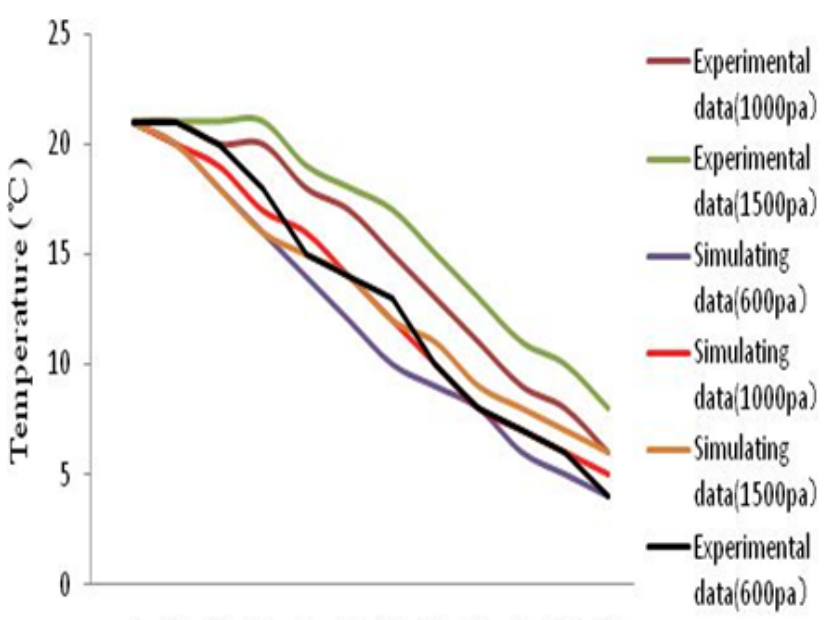

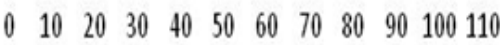

$$
\text { Time (s) }
$$

Figure 4. Temperature change in vacuum pre-cooling process under different pressures

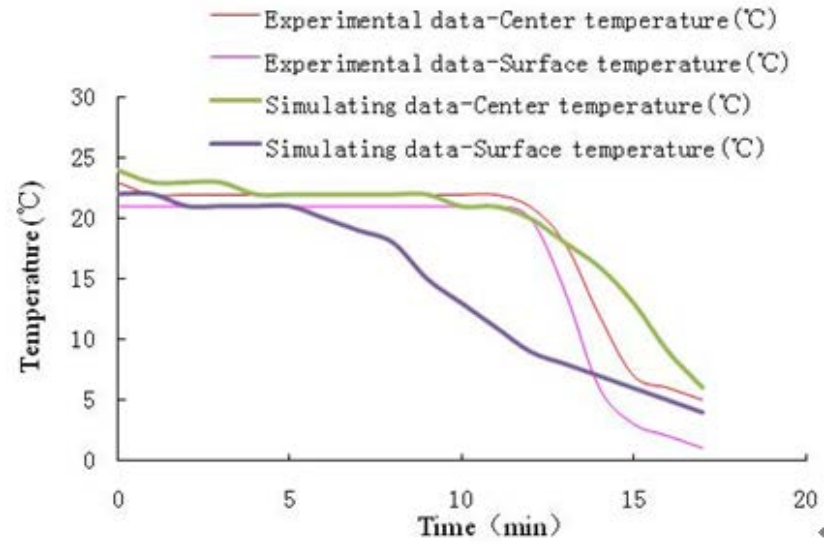

Figure 5. Temperature changes during vacuum pre-cooling of unsubmerged lettuce (Sample 1).

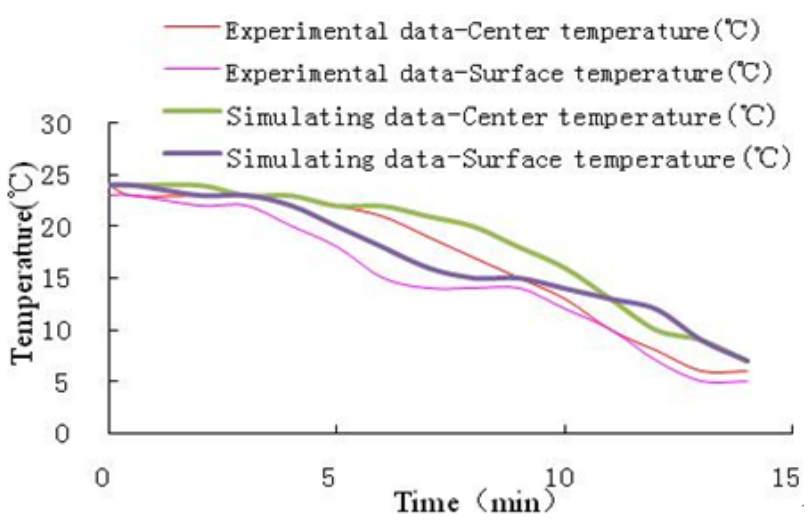

Figure 6. Temperature changes during vacuum pre-cooling of lettuce sprayed with $1.76 \mathrm{~g}$ water (Sample 2)

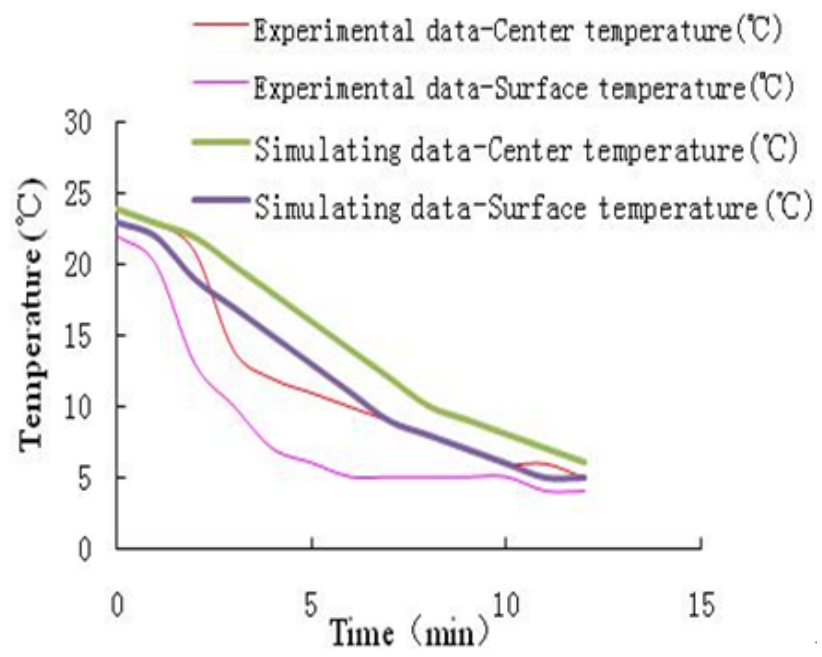

Figure 7. Temperature changes during vacuum pre-cooling of lettuce sprayed with $1.97 \mathrm{~g}$ water (Sample 3). 


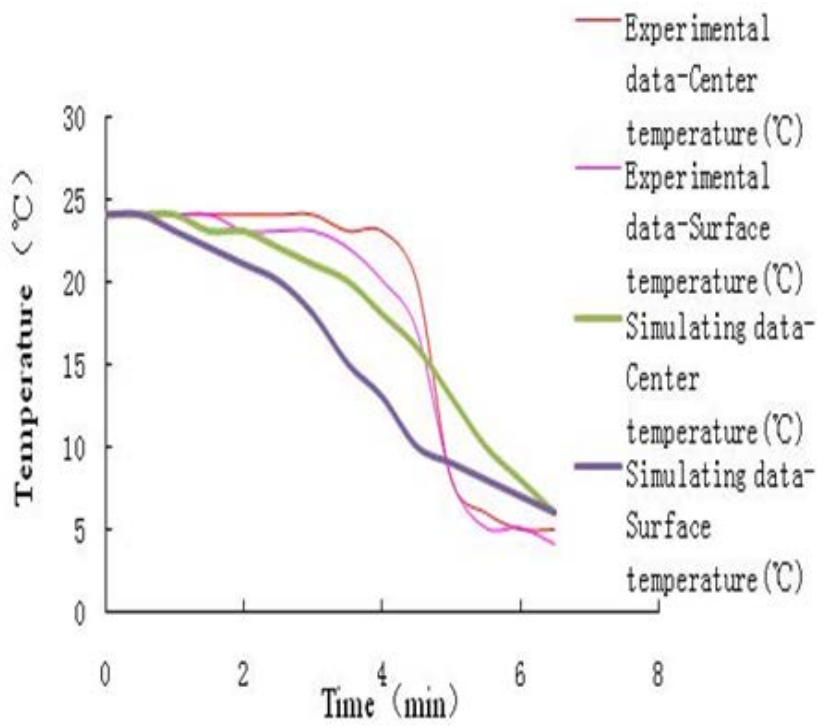

Figure 8. Temperature changes during vacuum pre-cooling of lettuce sprayed with $3.12 \mathrm{~g}$ water (Sample 4)

Based on the thermodynamic calculation, under lower vacuum pressure, the velocity of dehydration of leaf lettuce increased, while surface temperature decreased rapidly (Figure 4, Table 2). During the vacuum precooling process, the mass loss and speed of the evaporation showed that the lower the pressure, the faster the mass transfer process, and the more volatile the surface of the water. Comparing measured and simulated values, when samples were pre-stabilized, the medium gradually became faster than the analogue values of the pressure in the vacuum chamber: in the latter case, when the pressure in the vacuum chamber had stabilized, the pressure was higher than the measured analogue value.

Figure 5- Figure 8 and Table 1 show that the measured and the analogue values were substantially similar, and the general trends were similar in Figure 5 and 6. Rapid changes in the surface and internal temperatures occur in leaf lettuce during vacuum pre-cooling because of internal thermal and moisture diffusion. The processing time for pre-wetted samples was 10 min less than that of the control samples (Sample 1 in Table 1); when the quantity of water was increased the the pre-cooling time was reduced. The amount of water added to the test samples corresponded $4.211-5.977 \%$ of the total sample mass, and to a mass loss of $1.987-2.873 \%$. Under pre-cooling pressure of 600,1000 , and $1500 \mathrm{~Pa}$, the mass loss was 2.758, 2.701 and $1.929 \%$. The optimum percentage of spray water was $5 \%$ of the total sample mass, which corresponded to the best efficiency and optimum vacuum pre-cooling parameters for leaf lettuce.

\subsection{The Quantities of Capture Water and Cooling Capacity Calculation}

The compressor and vacuum pump are the main energy-consuming parts in vacuum pre-cooling. Here, we provide an analysis of an energy-saving method could be obtained based on controlling the load of compressor and start-stop of vacuum pump by the temperature or pressure. According to the above analysis and vapor condensation theory, the quantities of capture water of the pre-cooling unit is given by

$$
K_{n}=\frac{\lambda}{L}=\sqrt{\frac{\gamma \pi}{2}} \frac{M a}{\mathrm{Re}}
$$

In formula, $K_{n}$ is Knudsen Number, $L$ is the pipe diameter, $\mathrm{m}, M_{a}$ is Mach number, $\mathrm{Re}$ is Reynolds number, $\gamma$ is fouling factor, $m .{ }^{\circ} \mathrm{C} / W, \lambda$ is free path, and it can be expressed as

$$
\lambda=\frac{k T}{\sqrt{2} \pi d^{2} p}
$$

Where $k$ is Coefficient parameters, $d$ is diameter, $\mathrm{m}$, $p$ is Vacuum pressure, $\mathrm{Pa}$, and $T$ is temperature, ${ }^{\circ} \mathrm{C}$.

The quantities of capture water

$$
m=\frac{Q}{\gamma_{0}}
$$

In formula, $\gamma_{0}$ is latent heat, $\mathrm{kJ} / \mathrm{kg}, m$ is the quantities of capture water, $Q$ is heat transfer, $\mathrm{W}$, and according to the basic theory of mass transfer coefficients, the quantities of capture water of the leaf lettuce during vacuum pre-cooling can be written as:

$$
m=m_{1}+m_{2}
$$

Where $m_{1}=\sum_{i=1}^{5} m_{i}$ is steam consumption, $g$, and $m_{2}=\sum_{i=6}^{18} m_{i}$ is water consumption in evaporation, g.

$$
\varphi=\frac{m \gamma_{0}}{t}
$$

Where $\varphi$ is the cooling capacity, $\mathrm{W}, t$ is time, min.

Water-catcher was a key component, vacuum extracted with water vapor in the air and subject to capture water, trapping the water down, otherwise it would reduce the pump's performance affects the entire vacuum pre-cooling device performance. Based on the experimental data and the records of the pre-cooling unit, and following from equations (10) through (14), the calculated the quantities of capture water was $1.607-2.567 \mathrm{~g}$, and the cooling capacity of the total sample was 3.722-5.946 W.

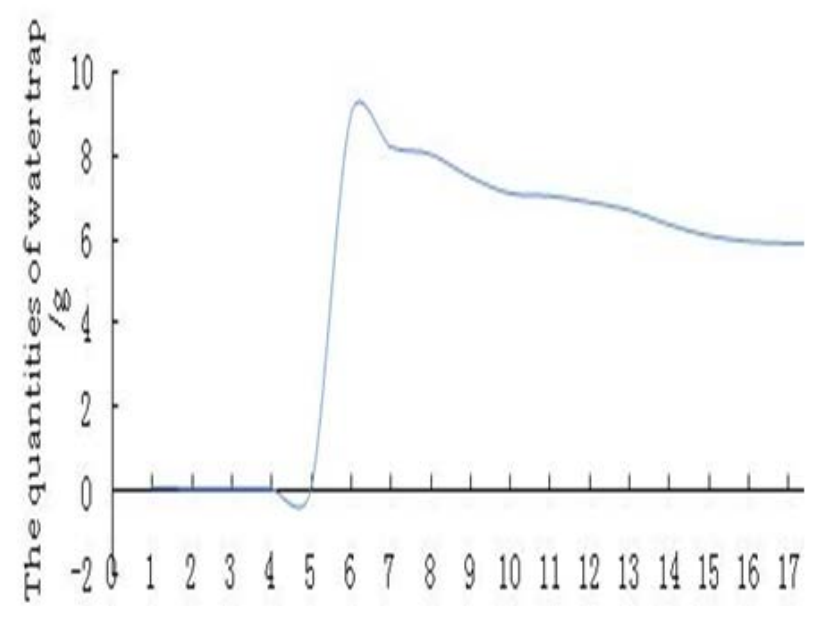

Figure 9. The quantities of capture water during vacuum pre-cooling 


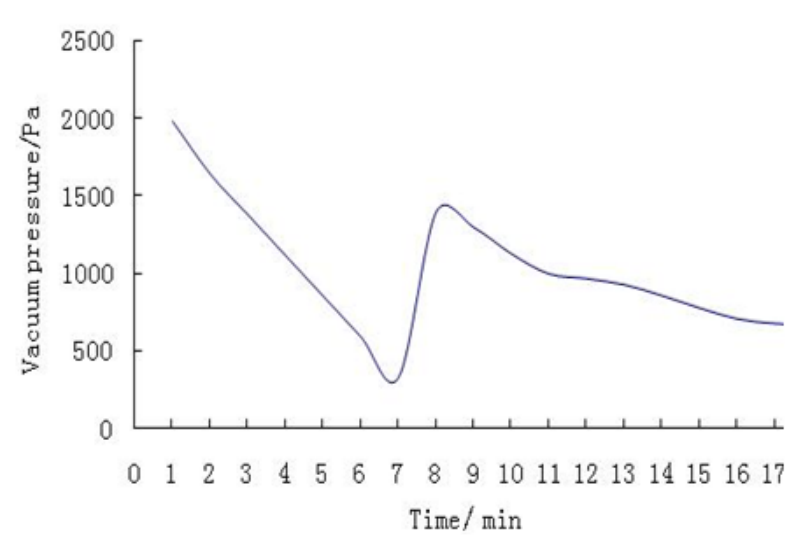

Figure 10. The curves of pressure changing with time

Figure 9- Figure 10 show that the temperature of leaf lettuce reduced, moisture evaporation in the process of vacuum pre-cooling, along with the pressure drop in vacuum tank. Compared with the edges, as the pressure in vacuum tank drops rapidly, the range of temperature drop is relatively large and fast, along with the moisture evaporation of leaf lettuce in center becomes bigger. The water content in leaf lettuce influences the dissipation of the vapor, and so it also influences the pre-cooling temperature and the weigh loss of leaf lettuce. The calculation results showed that the lower the vacuum pressure, the greater the cooling rate lettuce and water loss rate in vacuum pre-cooling process.

\section{Conclusions}

An experimental study using an unsteady computational model to analyze the factors affecting vacuum pre-cooling of leaf lettuce was conducted to perform quantitative analyses of economic and technical indices. Selecting the appropriate vacuum pressure, and quantity and rate of water application, and controlling the water loss during the pre-cooling process are important parameters for improving the product quality. The measured and simulated values were similar, along with the overall trends. The analyses and the results could be useful for operating vacuum pre-cooling. The conclusions are as following

(1) Under vacuum chamber pressures of 600,1000 , and $1500 \mathrm{~Pa}$, the internal and surface temperatures could be reduced during pre-cooling to a storage temperature of $5^{\circ} \mathrm{C}$; the internal cooling rate decreased and evaporation increased first after which the surface cooling rate gradually decreased. Pre-wetted lettuce reduced the precooling time during vacuum cooling by 10 minutes.

(2) The amount of water added to the test samples corresponded to $4.211-5.977 \%$ of the total sample mass, and to a mass loss of $1.987-2.873 \%$. Under pre-cooling pressure of 600,1000 , and $1500 \mathrm{~Pa}$, the mass loss was 2.758, 2.701 and $1.929 \%$. The calculation results showed that the quantities of capture water of the water-catcher was $1.607-2.567 \mathrm{~g}$, and the cooling capacity of the total sample was 3.722-5.946W in vacuum pre-cooling process.

\section{Acknowledgment}

This work was supported by the Zhengzhou City Scientific Research and Innovation Program
(131PCXTD588) and Henan province science and technology plan of innovative talents (2014HNSKJCXJCRC015) of China.

\section{Reference}

[1] Acker, R., Ball, K. M. (1977). Modulated vacuum cooling and vacuum treatment of bakery products. Getreide Mehl und Brot, 31, 134-138.

[2] Anon, (1981a). Vacuum cooling for fruits and vegetables. Food Processing Industry, 12, 24.

[3] Barger, W. R. (1961). Factors affecting temperature reduction and weight-loss in vacuum cooled lettuce. Marketing Research Report No. 469, United States Department of Agriculture (pp. 5-20).

[4] Brosnan, T., Sun, D.W.,2001. Pre-cooling techniques and applications for horticultural products. International Journal of Refrigeration 24, 154-170.

[5] Brosnan, T., Sun, D.W., 2003. Influence of modulated vacuum cooling on the cooling rate, mass loss and vase life of cut lily flowers. Biosystems Engineering 86 (1), 45-49.

[6] Chourasia, M.K., Goswami, T.K., 2007. Steady state CFD modeling of airflow, heat transfer and moisture loss in a commercial potato cold store. International Journal of Refrigeration. 30, 672-689.

[7] Chourasia, M.K., Goswami, T.K., 2007. Three dimensional modeling on airflow, heat and mass transfer in partially impermeable enclosure containing agricultural produce during natural convective cooling. Energy Conversion and Management. 48, 2136-2149.

[8] Demir, H., Mobedi, M., Ulku, S., 2010. The use of metal piece additives to enhance heat transfer rate through an unconsolidated adsorbent bed. Int. J. Refrigeration 33, 714-720.

[9] Deng, D., Xu, L., Xu, S., 2003. Experimental investigation on the performance of air cooler under frosting conditions. Appl. Therm. Eng. 23, 905-912.

[10] Evans, J., Russell, S., James, S., 1996. Chilling of recipe dish meals to meet cook-chill guidelines. International Journal of Refrigeration. 19, 79-86.

[11] Foster, A.M., Barrett, S.J., James, J., Swain, M.J., 2002. Measurement and prediction of air movement through doorways in refrigerated rooms. International Journal of Refrigeration 25 (8), 1102-1109.

[12] Foster, A.M., Swain, M.J., Barrett, R., James, S.J., 2003. Experimental verification of analytical and CFD predictions of infiltration through cold store entrances. International Journal of Refrigeration 26 (8), 918-925.

[13] Guo, A., Zhao, H., Lin, H., 1999. Vacuum pre-cooling properties of Chinese cabbage and Chinese kale. In Proceedings of the 99 International Conference on Agricultural Engineering, Beijing, China.

[14] Habib, K., Saha, B.B., Chakraborty, A., Koyama, S., Srinivasan, K., 2001. Performance evaluation of combined adsorption refrigeration cycles. Int. J. Refrigeration 34, 129-137.

[15] Haas, E., Gur, G., 1987. Factors affecting the cooling rate of lettuce in vacuum cooling installations. International Journal of Refrigeration 10, 82-86.

[16] Hand, L. W., Hollingsworth, C. A., Calkins, C. R., Mandigo, R. W.(1987). Effects of preblending, reduced fat and salt levels on frankfurter characteristics. Journal of Food Science, 52, 11491151.

[17] He, S.Y., Zhang, G. C., Yu, G. C., et al., 2013. Effects of vacuum cooling on the enzymatic antioxidant system of cherry and inhibition of surface-borne pathogens. International Journal of Refrigeration 36, 2387-2394.

[18] Ho, S.H., Rosario, L., Rahman, M.M., 2010. Numerical simulation of temperature and velocity in a refrigerated warehouse. International Journal of Refrigeration 33, 1015-1025.

[19] Houska, M., Landfeld, A., Sun, D.W., 2005. Eating quality enhancement of cooked pork and beef by ripening in brine and vacuum cooling. Journal Food Engineering 68 (3), 357-362.

[20] Hu, Z., Sun, D.W., 2001. Predicting local surface heat transfer coefficients by different turbulent $k-\varepsilon$ models to simulate heat and moisture transfer during air-blast chilling. Int. J. Refrigeration 24, 702-717.

[21] Jackman, P., Sun, D.W., Zheng, L., 2007. Effect of combined vacuum cooling and air blast cooling on processing time and 
cooling loss of large cooked beef joints. Journal Food Engineering 81, 266-271.

[22] Jame A Bartsch and G David Blanplied., (1984). Refrigeration and controlled atmosphere storage for horticultural crops. Northeast Regiomoal Agricultural Engineering Service. USA.

[23] Kondjoyan, A., 2006. A review on surface heat and mass transfer coefficients during air chilling and storage of food products. International Journal of Refrigeration 29 (6), 863-875.

[24] Kramer, A., Twigg, B. A. (1970). Fundamentals of quality control for the food industry (2nd ed.). Westport, Connecticut, USA: AVI Publishing Co.

[25] Kumano, H., Asaoka, T., Saito, A., Okawa, S., 2007. Study on latent heat of fusion of ice in aqueous solutions. International Journal of Refrigeration 30 (2), 267-273.

[26] Lutz JM, Hardenburg RE., (1986). The commercial storage of fruits, vegetables, and florist and nursery stocks. In: USDA agriculture handbook (no. 66) Washington, DC: USDA, P. 55-67.

[27] Martens, H., Martens, M. (2001). Multivariate analysis of quality. An introduction. London, UK: Wiley.

[28] McDonald, K., Sun, D.W., 2000. Vacuum cooling technology for the food processing industry. Journal of Food Engineering 45, 5565.

[29] McDonald, K., Sun, D.W., Kenny, T., 2000. Comparison of the quality of cooked beef products cooled by vacuum cooling and by conventional cooling. Lebensmittel Wissenschaft and Technologies 33, 21-29.

[30] Nahor, H.B., Hoang, M.L., Verboven, P., Baelmans, M., Nicolaï, B.M., 2005. CFD model of the airflow, heat and mass transfer in cool stores. International Journal of Refrigeration 28, 368-380.

[31] Rennie, T. J., Raghavan, G. S. V., Vigneault, C., 2001. Vacuum cooling of lettuce with various rates of pressure reduction. Journal of Electronic Packaging 44, 89-93.

[32] Rouaud, O., Haver, M., 2002. Computation of the air flow in a pilot scale clean room using $k-\varepsilon$ turbulence models. Int. J. Refrigeration 25, 351-361.

[33] Schmidt, F.C., Aragāo, G.M.F., Laurindo, J.B., 2010. Integrated cooking and vacuum cooling of chicken breast cuts in a single vessel. Journal of Food Engineering 100, 219-224.

[34] Smale, N.J., Moureh, J., Cortella, G., 2006. A review of numerical models of airflow in refrigerated food applications. International Journal of Refrigeration 29 (6), 911-930.

[35] Solmus, I., Rees, D.A.S., Yamalı, C., Baker, D., Kaftanoglu, B., 2012. Numerical investigation of coupled heat and mass transfer inside the adsorbent bed of an adsorption cooling unit. Int. J. Refrigeration 35, 652-662.

[36] Sun, D.W., 2000. Experimental research on vacuum rapid cooling of vegetables. In Advance in the refrigeration systems, food technologies and cold chain (pp. 342-347). Paris, France: International Institute of Refrigeration.

[37] Sun, D.W., Brosnan, T., 1999. Extension of the vase life of cut daffodil flowers by rapid vacuum cooling. International Journal of Refrigeration 22, 472-478.
[38] Sun, D.W., Hu, Z. H., 2003. CFD simulation of coupled heat and mass transfer through porous foods during vacuum cooling process. International Journal of Refrigeration 26, 19-27.

[39] Sun, H., Qi, Z. G., Zhang, J., Deng, D.Q., 2003. The experimental research of vacuum precooling. In: Cryogenics and RefrigerationProceedings of ICCR. Hongzhou, China, pp. 830-833.

[40] Sun, D.W., Weng, L.J., 2000. Heat transfer characteristic of cooked meats using different cooling methods. International Journal of Refrigeration 23 (7), 508-516.

[41] Sun, D.W., Zheng, L., 2006. Vacuum cooling technology for the agi-food industry: past, present and future. Journal Food Engineering 77, 203-214.

[42] Tao, F., Zhang, M., Hangqing, Y., 2006. Effects of differen storage conditions on chemical and physical properties of white mushrooms after vacuum cooling. Journal Food Engineering 77 (3), 545-549.

[43] Wang, CC., Chang, CT., 1998. Heat and mass transfer for plate fin-and-tube heat exchangers, with and without hydrophilic coating. Int J Heat Mass Transfer 41, 3109-3120.

[44] Wang, H., Touger, S., 1990. Distributed dynamic modeling of a refrigerated room. International Journal of Refrigeration 13, 214222

[45] Wang, L.J., Sun, D.W., 2001. Rapid cooling of porous and moisture foods by using vacuum cooling methods. Trends in Food Science and Technology, 12, 174-184.

[46] Wang, L.J., Sun, D.W., 2002. Modeling vacuum cooling process of cooked meat-part 1: Analysis of vacuum cooling system. Int. J. Refrigeration 25, 854-861.

[47] Wang, L.J., Sun, D.W., 2002. Modeling vacuum cooling process of cooked meat-part 2: mass and heat transfer of cooked meat under vacuum pressure. Int. J. Refrigeration 25, 862-871.

[48] Wang, L.J., Sun, D.W., 2003. Numerical analysis of the three dimensional mass and heat transfer with inner moisture evaporation in porous cooked meat joints during vacuum cooling process. Transactions of the ASAE 46 (1), 107-115.

[49] Yang, Z., Xu, XL., Li, XH., 2007. Simulation and experiment on the unsteady 3D flow field of cool store. J Tianjing Univ Sci Technol 40, 157-162.

[50] Yin, Y.G., Zhang, X. S., 2008. A new method for determining coupled heat and mass transfer coefficients between air and liquid desiccant. International Journal of Heat and Mass Transfer 51, 3287-3297.

[51] Zhang, Z., Sun, D.W., 2006. Effect of cooling methods on the cooling efficiencies and qualities of cooked broccoli and carrot slices. Journal of Food Engineering 77, 320-326.

[52] Zhang, Z.H., Drummond, Liana., Sun, D.W., 2013. Vacuum cooling in bulk of beef pieces of different sizes and shapeEvaluation and comparison to conventional cooling methods. Journal of Food Engineering 116, 581-587.

[53] Zhou, G., Zhang, Y., 2006. Numerical and experimental investigation on the performance of coiled adiabatic capillary tubes. Appl. Thermal Eng. 26, 1106-1114 